\title{
LOS TRATADOS INTERNACIONALES EN EL ORDEN JURÍDICO \\ MEXICANO
}

\section{Hugo PEREZCANO DÍAZ*}

RESUMEN: En la jerarquía de leyes del orden jurídico mexicano, en primer lugar se encuentra la Constitución, en segundo, los tratados, y finalmente las leyes federales y estatales. El sistema federal por el que México optó hace más de 130 años tiene como consecuencia esta jerarquía normativa.

ABSTRACT: According to Mexico's legal system hierarchy of norms, at the top stands the Constitution, followed by International Treaties, and then the Federal and Local laws. This hierarchy of norm derives from the Federal system adopted by Mexico more than 130 years ago.

RESUME: L'ordre juridique mexicain est dominé par la Constitution, après viennent les Traités et les lois fédérales, et les lois des états dans un troisième niveau. Cette hiérarchie des normes résulte du système fédéral choisi par le Mexique depuis plus de 130 ans.

* Consultor jurídico de negociaciones, Secretaría de Economía, México. 
SUMARIO: I. Introducción. II. La supremacía de la Constitución. III. La jerarquía de los tratados internacionales. IV. Conclusión.

\section{INTRODUCCIÓN}

En octubre de 1999 la Suprema Corte de Justicia adoptó como criterio que, jerárquicamente, los tratados internacionales se encuentran en un segundo plano inmediatamente debajo de la Constitución y por encima del derecho federal y el local, éstos últimos, en tercer lugar, en una misma jerarquía. ${ }^{1}$ Expresamente abandonó la tesis de jurisprudencia vigente hasta entonces de que, en la jerarquía de las normas en el orden jurídico mexicano, tanto las leyes que emanen de la Constitución, como los tratados internacionales, ocupan, ambos, el rango inmediatamente inferior a la Constitución.

El nuevo criterio de la corte constituye una tesis aislada. La corte no ha vuelto a abordar el tema.

La corte sustenta su tesis en los siguientes razonamientos:

a) Los compromisos internacionales son asumidos por el Estado mexicano en su conjunto y comprometen a todas sus autoridades frente a la comunidad internacional, ya que el presidente de la República suscribe los tratados internacionales en su calidad de jefe de Estado y el Senado interviene como representante de la voluntad de las entidades federativas $\mathrm{y}$, por medio de su ratificación, obliga a sus autoridades.

b) La celebración de tratados no está sujeta a la limitación competencial entre la Federación y las entidades federativas establecida por el artículo 124 constitucional, puesto que el presidente de la República y el Senado pueden obligar al Estado mexicano en su conjunto en cualquier materia, independientemente de que para otros efectos ésta sea competencia de las entidades federativas.

La corte desprende la mayor jerarquía de los tratados internacionales de la interpretación del artículo 133 constitucional a la luz de su evolución histórica y el papel que desempeña el Estado mexicano ante la co-

1 Tratados internacionales. Se ubican jerárquicamente por encima de las leyes federales y en un segundo plano respecto de la Constitución federal. Suprema Corte de Justicia de la Nación, Tesis P. LXXVII/99, Semanario Judicial de la Federación, noviembre de 1999, p. 46. 
munidad internacional. Su conclusión en esencia deriva de dos cuestiones que da por sentadas, pero sobre las cuales no ofrece un análisis: la capacidad con la que intervienen el presidente de la República y el Senado en el proceso de adopción de tratados internacionales, y el que los tratados internacionales escapan a limitación de competencias prevista en el artículo 124 de la Constitución.

Sin embargo, la posición que los tratados internacionales ocupan en orden jurídico mexicano no deriva únicamente del artículo 133, en relación con los artículos 76 , fracción I y 89 , fracción $\mathrm{X}$ de la carta magna. El análisis es más complejo. Para resolver las interrogantes sobre la posición que ocupan los tratados en el orden jurídico y el ámbito de los mismos en función de la distribución de competencias, es preciso analizar varios artículos más de la Constitución, en el contexto, no sólo de su evolución histórica, sino también del régimen federal mexicano.

\section{LA SUPREMACÍA DE LA CONSTITUCIÓN}

\section{Contexto histórico}

La estructura del sistema jurídico mexicano está dada primeramente por el artículo 133 de la Constitución que dispone:

Esta Constitución, las leyes del Congreso de la Unión que emanen de ella y todos los tratados que estén de acuerdo con la misma, celebrados y que se celebren por el presidente de la República, con aprobación del Senado, serán la ley suprema de toda la unión. Los jueces de cada Estado se arreglarán a dicha Constitución, leyes y tratados, a pesar de las disposiciones en contrario que pueda haber en las Constituciones o leyes de los Estados.

La supremacía constitucional se estableció desde los inicios de la vida independiente de México. El Acta Constitutiva de la Federación de enero de 1824 previó en su artículo 24: "Las Constituciones de los Estados no podrán oponerse a esta acta ni a lo que establezca la Constitución general: por tanto, no podrán sancionarse hasta la publicación de ésta última". La Constitución de 1824 recogió este principio, y también incorporó el de la supremacía de los tratados internacionales respecto del ámbito de los estados. El artículo 161 estipuló: 
Cada uno de los Estados tiene la obligación:

I. De organizar su gobierno y administración interior, sin oponerse a esta Constitución ni a la Acta Constitutiva.

III. De guardar y hacer guardar la constitución y las leyes generales de la unión, y los tratados hechos o que en adelante se hicieren por la autoridad suprema de la Federación con alguna potencia extranjera.

Puede apreciarse cierta similitud entre la fracción III del artículo 161 con el segundo párrafo artículo VI en la Constitución de los Estados Unidos de América de 1787, que dispone:

This Constitution, and the Laws of the United States which shall be made in Pursuance thereof; and all Treaties made, or which shall be made, under the Authority of the United States, shall be the supreme Law of the Land; and the Judges in every State shall be bound thereby, any Thing in the Constitution or Laws of any State to the Contrary notwithstanding.

La disposición puede traducirse de la siguiente forma:

Esta Constitución, y las leyes de los Estados Unidos que se hicieren en seguimiento de ella; y todos los tratados hechos o que se hicieren, bajo la potestad de los Estados Unidos, serán el derecho supremo de la nación; y los jueces en todo Estado estarán obligados por ellos, no obstante cualquier cosa en contrario en la Constitución o las leyes de cualquier Estado.

Al redactar el artículo 161 — como muchos otros-el Constituyente de 1824 se inspiró en la Constitución de Estados Unidos de América, pero incorporó un texto que tiene importantes diferencias. La supremacía de la Constitución se aprecia con mayor claridad que en el texto del artículo 133 de la Constitución vigente, que tantos debates ha suscitado. El artículo 161 no establece la supremacía de la Constitución en forma explícita; pero tampoco califica a la Constitución y las leyes generales del congreso de ley suprema. En este contexto, la fracción I del mismo artículo, aunado al artículo 163 que establece el deber de "[t]odo funcionario público, sin excepción de clase alguna" de prestar juramento y de guardar la Constitución y el Acta Constitutiva parecen apuntar con suficiente claridad a la supremacía constitucional.

El artículo 133 de la Constitución vigente tiene su origen en la Constitución de 1857, cuyo proyecto fue elaborado por la Comisión de Consti- 
tución del Congreso Constituyente instalado el 18 de febrero de 1856. El dictamen de la Comisión de Constitución no aborda la inclusión del artículo 123 del proyecto, que finalmente quedó aprobado como artículo 126 de la Constitución:

Artículo 126. Esta Constitución, las leyes del Congreso de la Unión que emanen de ella y todos los tratados hechos ó que se hicieren por el presidente de la República con aprobación del congreso, serán la ley suprema de toda la unión. Los jueces de cada Estado se arreglarán á dicha Constitución, leyes y tratados, á pesar de las disposiciones en contrario que pueda haber en las Constituciones ó leyes de los Estados.

A diferencia del Constituyente de 1824, el de 1857 recogió el texto del artículo VI, párrafo segundo de la Constitución de Estados Unidos de América, con ciertas modificaciones menores para adecuarla al resto del texto constitucional. En primer lugar, se precisó que se trataba de leyes del Congreso de la Unión, quizás para evitar cualquier duda que pudiese haber surgido de haber sustituido la referencia a las "Leyes de los Estados Unidos" por las "Leyes de los Estados Unidos Mexicanos", dadas las muy distintas circunstancias en las que surgieron nuestros respectivos federalismos, y particularmente la pugna continua que venía desarrollándose entre centralistas y federalistas, y que pretendía resolverse en definitiva precisamente con la nueva Constitución. Segundo, estableció la correlación de este artículo con el 64, inciso octavo (también del proyecto, artículo 72, fracción XIII de la Constitución aprobada) que establecía las facultades del Congreso de la Unión para "aprobar los tratados y convenios diplomáticos que celebre el Ejecutivo”, y el 86, inciso décimo (85, fracción X de la Constitución aprobada) que establecía la del Ejecutivo de "dirigir las negociaciones diplomáticas conforme á las instrucciones que reciba del congreso federal, y celebrar tratados con las potencias extranjeras, sometiéndolos á la ratificación del mismo congreso", precisando que serían "ley suprema en toda la unión" los tratados suscritos por el presidente de la República, con aprobación del congreso. Finalmente, la comisión modificó la frase "Supreme Law of the Land" para referirse al Estado federado designado como "unión". Sin embargo, la traducción de la frase no fue la más afortunada. El término "law" puede traducirse al español como "ley", entendida en términos simples como una norma general, abstracta, que emana de un órgano legislativo del Estado; pero también "derecho", entendido, en términos simples, como 
el conjunto de normas reconocidas como obligatorias y que el Estado puede imponer en forma coactiva. El texto constitucional estadounidense distingue entre "the laws of the United States", donde utiliza el plural y claramente se refiere a las leyes, y "the supreme Law of the Land", donde emplea el singular y el contexto indica más bien que se utiliza en su acepción de "derecho".

El artículo 126 de la Constitución de 1857 permaneció inalterado. El proyecto de Constitución reformada que presentó Venustiano Carranza al Constituyente de 1917 no lo recogió. Al respecto, la Comisión de Constitución expresó en su dictamen:

Más importante aún es el artículo 123 [sic] de la Constitución de 1857, también suprimido en el proyecto, que establece la supremacía de la Ley constitucional, de las leyes emanadas de está y de los tratados hechos por el Ejecutivo con aprobación del congreso. La ley americana, en un precepto análogo, hace uso de la expresión enérgica, diciendo que leyes como éstas son la ley suprema de la tierra. Así es entre nosotros también, y el artículo suprimido, además de esa grandiosa declaración, constituye la salvaguardia del pacto federal y su lugar preferente respecto de las Constituciones locales, pues autoriza a los jueces para ceñirse a aquél, a pesar de disposiciones en contrario que pueda haber en éstas.

No obstante, su inclusión fue poco meditada. El artículo fue aprobado por unanimidad de 154 votos, sin discusión alguna. Se incorporó con el mismo texto que tenía en la Constitución de 1857 y acarreó un error de ésta, que no fue corregido sino hasta 1934, 17 años después: pese a que la Constitución de 1857 facultó al Senado para aprobar los tratados internacionales, el artículo 133 conservó la referencia errónea al Congreso de la Unión contenida en la Constitución de 1857, que omitió ser corregida tras la reinstalación del Senado en 1874.

\section{La supremacía de la Constitución en el texto vigente de la carta magna}

Tanto la doctrina como la jurisprudencia en general coinciden en que la Constitución es la norma suprema y que la supremacía está anclada esencialmente en el artículo 133 constitucional, aunque se desprende también de los artículos 41, que contiene el principio de la distribución de competencias entre los poderes de la unión y los de los Estados, en re- 
lación con el 124 que la establece; el 128 que dispone que todo funcionario deberá rendir protesta de guardar la Constitución y las leyes que de ella emanen; y el 135 que establece un procedimiento especial para la adición y reforma de la Constitución. ${ }^{2}$

Sin embargo, no parece haber habido siempre tal coincidencia. Óscar Rabasa, el autor de la reforma de 1934 al artículo 133, comentó:

Se tuvo en cuenta la conveniencia de disipar dudas y confusiones que suscitaba el laconismo anglosajón del texto primitivo del artículo 133 de nuestra Constitución. Surgía la primera duda respecto a si la Constitución y los tratados eran de jerarquía igual o si había diverso rango entre la primera y los segundos, sólo porque en el texto a ambos tipos de ordenamiento se les declaraba ley suprema. Más aún: Se llegó a suponer que los tratados internacionales ocupaban rango superior al de la Constitución, sin parar mientes en que, si esta conclusión jurídica es correcta desde el plano del derecho internacional, no lo es desde el ángulo del derecho interno, que en México está integrado fundamentalmente por la Constitución... [y] [é]sta expresamente dispone que ella es ley suprema, en toda la nación y cuando establece que los tratados también lo serán, es claro que tal cosa es cierta siempre y cuando se ajusten a los preceptos expresos de la propia ley fundamental. ${ }^{3}$

La Comisión de Puntos Constitucionales de la Cámara de Diputados expresó al respecto en su dictamen:

Es obvia la razón que se ha tenido en cuenta para reformar el artículo 133 de la Constitución en la forma propuesta por el Ejecutivo y que el Senado acepta, pues si bien es verdad que los tratados internacionales también son ley suprema de la unión, esto es, en cuanto no estén en pugna con la ley fundamental que es la Constitución. ${ }^{4}$

2 Voz: "Supremacía de la Constitución”, Diccionario jurídico mexicano, 2a. ed., México, Porrúa-UNAM, 1988, vol. IV, pp. 3023-3025; Carpizo, Jorge, Estudios constitucionales, 6a. ed., México, UNAM, 1998, pp. 17 y 18; Arteaga Nava, Elisur, Derecho constitucional, México, UNAM, 1994, t. III, p. 120.

3 Pereznieto, Leonel, "El artículo 133 constitucional: una relectura", Anuario del Departamento de Derecho de la Universidad Iberoamericana, núm. 25, t. II, 1995, p. 273.

4 El dictamen de las Comisiones Unidas, Segunda de Puntos Constitucionales y Segunda de Justicia del Senado no aludió a la propuesta de reforma al artículo 133 
Algunos autores, incluido el propio Óscar Rabasa, opinan que los tratados internacionales que estén de acuerdo con la Constitución adquieren la misma jerarquía que ésta. ${ }^{5}$ Pereznieto explica que si se salva el requisito de que los tratados sean conformes a la Constitución, entonces son ley suprema de la unión y el artículo 133 los ubica al mismo nivel jerárquico de aquella. ${ }^{6}$ Sin embargo, en la pirámide kelseniana la exigencia en la Constitución de que los tratados sean acordes con ella desvela la supremacía de la misma sobre éstos. Así lo han entendido la mayoría de los autores y actualmente las dudas que la redacción original del artículo 133 pudo haber generado sobre la supremacía de la Constitución parecen haberse disipado. La opinión actual generalizada es que la reforma de 1934 estableció con claridad la supremacía de la Constitución.

Ahora bien, debe precisarse que la jerarquía normativa sólo es relevante en caso de que exista contradicción de normas. Si los tratados no están conformes con la Constitución, no quiere decir que caigan en la jerarquía de normas, sino que puede solicitarse por la vía judicial la declaratoria de inconstitucionalidad y el tratado - o la norma contraria específica del mismo - dejaría de aplicarse en términos de la Ley de Amparo. ${ }^{7}$ Empero, si el tratado es acorde a la Constitución, entonces su jerarquía frente a ella deviene irrelevante; el problema de la jerarquía normativa no se presenta.

\section{LA JERARQUÍA DE LOS TRATADOS INTERNACIONALES}

Puesto que la estructura del orden jurídico mexicano está determinada, según se dijo, por la Constitución, la posición jerárquica que ocupan los tratados en el mismo es una tema de derecho constitucional. En la ejecutoria que dio origen a la tesis de 1999 de la Suprema Corte de Justi-

constitucional presentada por el Ejecutivo, que fue parte de una iniciativa para reformar también los artículos 73, fracción XXI y 107.

5 Pereznieto, Leonel, op. cit., nota 3.

6 Ibidem, p. 280.

7 Cfr. Carpizo, Jorge, op. cit., nota 2, p. 25. Carpizo comenta que "un tratado anticonstitucional no se puede aplicar en el orden interno, ya que la Constitución es la suprema y los tratados se encuentran en escaño inferior". Esta posición es inexacta porque un tratado inconstitucional, pero que ha sido celebrado por el presidente y aprobado por el Senado, es aplicable mientras no se establezca su inconstitucionalidad, lo mismo que una ley inconstitucional del Congreso de la Unión. 
cia sobre la jerarquía de los tratados, la corte abordó también el sistema de recepción de los tratados internacionales por el derecho mexicano. En este contexto aludió a ciertas disposiciones de la Convención del Viena sobre el Derecho de los Tratados relativas a la obligatoriedad de éstos, con el propósito de ilustrar sus razonamientos sobre la vigencia del derecho internacional en México. Este último tema no es materia del presente análisis, pero es pertinente mencionarlo simplemente para precisar que las cuestiones de recepción por el derecho mexicano del derecho internacional y la jerarquía normativa de los tratados en nuestro orden jurídico, no pueden desprenderse del derecho internacional. La Convención de Viena se refiere, entre otras materias, a la obligatoriedad de los tratados en el plano internacional exclusivamente. No pretende resolver cuestiones, y mucho menos establecer reglas, relativas a la aplicación de los tratados en los sistemas jurídicos nacionales. Ello es una cuestión de derecho interno que, en México, debe resolverse a partir de la Constitución. ${ }^{8}$

\section{Contexto histórico de la relación entre los ámbitos federal $y$ locales}

La Constitución de 1824 también era clara sobre la primacía de la legislación federal sobre la local. El artículo 161 estableció la obligación de los estados de guardar y hacer guardar la Constitución y las leyes generales de la unión. Con toda claridad se refiere a las leyes generales de la unión, es decir, a todas las leyes federales. El texto de la Constitución de 1824 es más preciso que el correlativo de la Constitución estadounidense que se refiere a las "Leyes de los Estados Unidos".

Estableció igualmente la primacía de los tratados internacionales sobre la legislación local; pero no es explícita en cuanto a la relación entre las leyes generales de la unión y los tratados internacionales. Debe advertirse, no obstante, que la celebración de tratados era "por la autoridad suprema de la Federación". En este sentido también, el Constituyente se inspiró en la Constitución de Estados Unidos de América, pero incorporó una fórmula distinta. La Constitución estadounidense confirió al presidente la facultad de celebrar tratados "por y con el consejo y el consenti-

8 Cfr. Cossío Díaz, José Ramón, "La nueva jerarquía de los tratados internacionales", Este País, México, febrero de 2000, p. 36. 
miento del Senado". ${ }^{9}$ La Constitución de 1824, sin embargo, distinguió entre la facultad del presidente - en quien se depositó el supremo Poder Ejecutivo - de celebrar tratados y la del Congreso General de aprobarlos. Sólo en el caso de los concordatos con la silla apostólica se dio la facultad al congreso de dar instrucciones al presidente para su celebración, además de "aprobarlos para su ratificación". Respecto de los demás tratados internacionales, la facultad del congreso se limitó a aprobarlos.

La Constitución de 1824 no estableció una división precisa de competencias entre los estados y la Federación. Estableció las facultades de los poderes federales, y para los estados estableció ciertas obligaciones y prohibiciones. Sin embargo, no incorporó el principio de distribución de competencias contemplado en la décima enmienda de la Constitución de Estados Unidos de América, como lo haría el Constituyente de 1857, que lo hizo casi en los mismos términos. La enmienda prevé: "The powers not delegated to the United States by the Constitution, nor prohibited by it to the States, are reserved to the States respectively, or to the people".

El texto puede traducirse de la siguiente forma: "Las facultades que no han sido delegadas en los Estados Unidos por la Constitución, ni están prohibidas por ésta para los Estados, están reservadas a los Estados respectivamente, o al pueblo".

El texto del artículo 117 es el siguiente: "Las facultades que no están espresamente concedidas por esta Constitución á los funcionarios federales, se entienden reservadas a los estados".

Si bien la Comisión de Constitución tuvo el cuidado de analizar la relación entre el artículo 123 y los artículos 64 y 86 de su proyecto (correspondientes a los artículos 126, 72 y 85 de la Constitución aprobada), el Constituyente no tuvo la misma precaución de analizar la relación del artículo 126 con el artículo 117 (que corresponde al 124 de nuestra Constitución vigente) y que estaba ausente del proyecto de la comisión. Debe advertirse que la Constitución estadounidense originalmente tampoco contenía la cláusula de distribución de competencias entre la Fede-

9 La Constitución de Estados Unidos de América dispone en el segundo párrafo de la segunda sección del artículo II: "He [the President] shall have Power, by and with the Advice and Consent of the Senate, to make Treaties, provided two thirds of the Senators present concur". Esta disposición puede traducirse de la siguiente forma: "[El presidente] tendrá la facultad, por y con el consejo y el consentimiento del Senado, de celebrar tratados, siempre que dos tercios de los senadores presentes concurran". 
ración y los estados. ${ }^{10}$ Ésta fue producto de la décima enmienda de 1791, de modo que la relación entre la jerarquía de leyes y la distribución de competencias tampoco fue analizada por los delegados de la convención federal de ese país.

El Constituyente de 1857 no adaptó simplemente el texto de la Constitución estadounidense. Lo incorporó con las siguientes modificaciones que deben destacarse. Primero, añadió la palabra "espresamente" (contenida en el artículo II de los artículos de Confederación de Estados Unidos de América), con lo cual acotó con precisión la competencia del gobierno federal. Segundo, eliminó la reserva que la Constitución de Estados Unidos de América hizo al pueblo.

La Constitución de 1917 incorporó en el artículo 124 el texto del 117 de la Constitución de 1857, sin modificaciones. No ha sido reformado.

Las modificaciones con las que el Constituyente de 1857 incorporó el texto de la enmienda décima de la Constitución estadounidense tienen implicaciones importantes y marcan una diferencia significativa en el desarrollo constitucional de México y Estados Unidos de América, respectivamente. Mientras que para Estados Unidos de América la interacción entre el artículo sexto y la décima enmienda constitucionales permite que los gobiernos federal y locales concurran respecto de ciertas materias (aquellas que no están reservadas expresamente a la Federación ni prohibidas para los Estados), ${ }^{11}$ México adoptó un sistema rígido de distribución de competencias entre los estados y la Federación, donde los ámbitos respectivos están claramente separados. El artículo 124 establece un sistema de jurisdicción dual donde, si la Constitución ha atribuido una

10 Estados Unidos de América ha tenido dos Constituciones: los artículos de Confederación, que fueron aprobados el 9 de junio de 1777 y entraron en vigor el 1 o. de marzo de 1781, tras haber sido ratificados por todos los estados; y la Constitución aprobada el 17 de septiembre de 1787, que entró en vigor el 21 de junio de 1788. Esta última reemplazó a los artículos de Confederación. La Constitución de Estados Unidos de América no recogió el artículo II de los artículos de Confederación que contenía la cláusula de distribución de competencias en los siguientes términos: "Each state retains its sovereignty, freedom, and independence, and every power, jurisdiction, and right, which is not by this Confederation expressly delegated to the United States, in Congress assembled". El texto puede traducirse como sigue: "cada estado conserva su soberanía, libertad e independencia, y toda facultad, competencia y derecho, que no haya sido expresamente delegada por esta Confederación a los Estados Unidos de América, reunidos en congreso".

11 Cfr. Carpizo, Jorge, op. cit., nota 2, pp. 21 y 22. 
facultad a funcionarios federales, necesariamente está prohibida para los poderes locales. ${ }^{12}$ No hay traslape entre los ámbitos federal y local, con excepción de aquellos casos donde la Constitución expresamente establece la concurrencia del gobierno federal y los gobiernos locales, por ejemplo, en materia de asentamientos humanos (artículo 73, fracción XXIX-C), protección al ambiente y preservación y restauración del equilibrio ecológico (artículo 73, fracción XXIX-G) o protección civil (artículo 73, fracción XXIX-I).

La supremacía de un orden sobre el otro no se plantea. Si hubiere una contradicción entre una norma federal y una local, se trata de un problema de competencia y habrá que discernir a qué autoridad le está conferida. ${ }^{13}$ En consecuencia el artículo 133 de la Constitución tiene un alcance muy distinto que el párrafo segundo del artículo sexto de la Constitución estadounidense.

\section{El Senado}

\section{A. Contexto histórico}

La Constitución de 1857 inicialmente estableció un sistema unicameral. Sin embargo, en 1874 sufrió una importante reforma: reestableció el sistema bicameral previsto en los anteriores textos constitucionales, pero fue más lejos que éstos al investir al Senado del importante papel que hoy desempeña en nuestro régimen federal.

Hasta antes de esa fecha, las Constituciones mexicanas habían otorgado al Senado un papel menos preponderante. La Constitución de 1824 estableció dos cámaras con prácticamente las mismas atribuciones: participar en el proceso de formación de leyes y erigirse en gran jurado en el juicio responsabilidades, la Cámara de Diputados como representante de los ciudadanos y la de Senadores, de los estados. En las leyes constitucionales de 1836 el papel del Senado se limitó esencialmente a ser la cámara revisora en el proceso de formación de leyes, aunque se le otorgó la facultad de aprobar los nombramientos del Ejecutivo de los agentes diplomáticos y los oficiales superiores del ejército, armada y milicia, y la de autorizar, en los recesos del congreso, la entrada a territorio nacional

12 Arteaga Nava, Elisur, Tratado de derecho constitucional, México, Oxford University Press, 1999, vol. 2, p. 579.

13 Cfr. Carpizo, Jorge, op. cit., nota 2, p. 23. 
de tropas extranjeras y la salida de tropas nacionales fuera del país. $\mathrm{Su}$ papel en materia de juicio de responsabilidades también se limitó a las acusaciones contra los diputados.

En 1867 se presentó al congreso una iniciativa de reformas para reestablecer el Senado. En una circular dirigida a los gobernadores de los estados, Sebastián Lerdo de Tejada expuso:

Es la opinión común que en una República Federal, sirven las dos cámaras para combinar en el Poder Legislativo el empleo popular y el elemento federativo. Una cámara de diputados, elegidos en número proporcional a la población, representa el elemento popular, y un Senado, compuesto de igual número de senadores por cada Estado, representa el elemento federativo.

La cuestión se debatió durante casi siete años. La comisión que dictaminó la iniciativa expresó:

Todas las consideraciones expuestas autorizan a la comisión a pensar que los efectos de la división del Poder Legislativo en dos cámaras serían altamente provechosos a la República: sus relaciones exteriores tendrán más firmeza y respetabilidad, las leyes serán el fruto de las deliberaciones más reposadas y extrañas a la festinación; los funcionarios públicos se contendrán en el límite de sus deberes, porque un jurado de sentencia será más numeroso, y por consiguiente más respetable; y por último la dictadura será menos frecuente entre nosotros.

En el federalismo mexicano, el Senado se concibió como el órgano que representa equitativamente a los estados en el congreso. Históricamente se ha integrado por el mismo número de senadores por cada entidad federativa, independientemente del número de habitantes que cada una tenga. La Constitución de 1824, inspirada en el modelo estadounidense, dispuso que el Senado se integraría por dos senadores de cada estado, elegidos por sus legislaturas por mayoría absoluta de votos (artículo 25). La Constitución de 1857 inicialmente estableció un sistema unicameral, pero las reformas de 1874 restablecieron el Senado, que se componía de dos senadores por cada estado, a través de una elección indirecta en primer grado, donde cada legislatura declaraba electo a quienes hubieran obtenido la mayoría absoluta de votos y, en caso contrario, elegiría a los senadores entre los que hubiesen obtenido una mayoría relativa (artículo 58, apartado A). 


\section{B. La representatividad del Senado}

\section{Burgoa opina:}

[D]entro de un régimen democrático, el Senado sólo puede legitimarse si la forma estatal en que se estructura es la federal, en que dicho órgano se integra con representantes de las entidades federativas. Bajo esta tesitura, el Senado constituye un cuerpo de equilibrio político que asegura su igualdad en lo que atañe, sobre todo, al ejercicio del Poder Legislativo... [C]on independencia de su población, todas las entidades federativas estuviesen paritariamente representadas a efecto de contrarrestar la fuerza de la cámara colegisladora. Estimamos que ésta es la más convincente razón que justifica el sistema bicamaral [sic] y únicamente dentro de un régimen federal.

El proyecto de Venustiano Carranza recogió la fórmula de la Constitución de 1857, pero el Constituyente de 1917 introdujo el principio de elección por mayoría relativa. Preservó, no obstante, la facultad de las legislaturas de declarar electos a los senadores (eliminada con la reforma de 1993). La reforma de 1993 al artículo 56 constitucional incrementó el número de senadores de dos a cuatro: tres eran electos por el principio de votación mayoritaria relativa y uno por el de la primera minoría. En 1996 se volvió a reformar el artículo 56 para incorporar el principio de la representación proporcional, de modo que dos senadores son electos por el principio de mayoría relativa, uno por el de primera minoría y uno por el de representación proporcional.

El sistema de elección directa de la Constitución de 1917 y particularmente la incorporación de senadores plurinominales han suscitado dudas sobre a quién representan actualmente los senadores. Raigosa plantea la interrogante en los siguientes términos:

La pregunta por la representación política del Senado tiene tras de sí un tema polémico, que quiere resolver si esta cámara sigue siendo o debería seguir siendo un órgano de representación de los estados, como presumiblemente lo fue hasta que se incorporó el sistema de representación proporcional en 1996, de manera que al Senado se le califica de órgano que cumple con una "función federalista". ${ }^{14}$

14 Raigosa Sotelo, Luis, Las funciones legislativas y no legislativas del Senado, México, Senado de la República-Instituto Tecnológico Autónomo de México-Miguel Ángel Porrúa, 2003, p. 185. 
Algunos autores afirman que, al igual que los diputados, los senadores representan a la población al ser ésta la que los elige por sufragio directo. ${ }^{15}$ Esta apreciación no parece correcta. La mayor democratización de la forma de integración del Senado no implica el abandono de la representación equitativa de los estados sobre el cual se concibió al Senado como órgano federal. Es cierto que las instituciones nacionales han tenido que irse ajustando a las realidades de nuestra historia. En México el federalismo ha pasado por un sistema político que fue dominado durante muchos años por un presidencialismo sumamente fuerte. Serna explica que la Presidencia ejerció una influencia determinante no sólo en la política local, sino en el Congreso de la Unión y hasta en la Suprema Corte de Justicia. ${ }^{16}$ Carpizo añade que, pese al sistema de elección, durante esta época los gobernadores eran designados por la voluntad del presidente de la República o de la oligarquía en el poder, y éstos a su vez designaban a los diputados locales a su arbitrio; no existía la autonomía de los poderes judiciales locales; y la designación de diputados y senadores al Congreso de la Unión no era diferente. ${ }^{17}$ Sin embargo, en nuestra larga transición hacia la democracia actualmente experimentamos un reequilibrio de poderes. El sistema de representación proporcional ha jugado un papel importante en este contexto. Dos quintos de los diputados y un cuarto de los senadores provienen de listas que los partidos políticos han integrado de manera enteramente discrecional. En nuestra realidad actual, donde no existe reelección inmediata en las cámaras, predomina un sistema de partidos y éstos pesan sobre la carrera política de quienes llegan al congreso, ya por elección directa, ya por la vía plurinominal, es absolutamente válida la pregunta de si la ciudadanía en realidad se ve representada por sus congresistas, no obstante el sufragio directo, universal por el que se les elige.

15 Cfr. Cossío Díaz, José Ramón, op. cit., nota 8, pp. 37 y 38: "El Senado de la República no representa desde hace mucho tiempo a las entidades federativas, en tanto la forma de elección de los senadores, su destitución, ejercicio de facultades, etcetera, no está ligado a los estados como tales, sino sencillamente a sus habitantes".

16 Serna de la Garza, José María, "Introducción al sistema federal", Examen retrospectivo del sistema constitucional mexicano a 180 años de la Constitución de 1824, México, UNAM, Instituto de Investigaciones Jurídicas, 2005, p. 15, formato PDF, disponible en http://www.bibliojuridica.org/libros/libro.htm?l=1671.

17 Carpizo, Jorge, La Constitución mexicana de 1917, 11a. ed., México, Porrúa, 1998, p. 238. 
Pero las instituciones deben resistir el paso del tiempo y la representación equitativa de los estados en el Senado ha sido el común denominador. Difícilmente puede entenderse la institución del Senado como representante de las entidades federativas, del presidente de la República, de los partidos políticos o de la ciudadanía, dependiendo del momento histórico en que se le analice. Los ajustes dictados por las realidades contemporáneas han tendido a ir consolidando la democracia y tenderán a hacerlo cada vez más. Es previsible que en el futuro cercano se acepte la reelección inmediata en las cámaras, lo cual contribuirá en forma importante a lograr una mayor representación de la ciudadanía. En el reequilibrio de poderes que vivimos, dos comienzan a ganar terreno: la ciudadanía y las entidades federativas. Serna comenta que la transición política ha generado una descompresión de fuerzas e ímpetus que durante muchos años permanecieron subordinados, lo cual ha motivado que se refuerce el reclamo por un Estado federal altamente descentralizado. ${ }^{18}$ En este contexto es perfectamente previsible que el fortalecimiento de las entidades federativas se reflejará también en una reafirmación de su papel a través del Senado. Ciertamente existen tendencias que apuntan en la dirección contraria de diluir el rol del Senado para fortalecer al congreso, seguramente no al grado de retomar el unicameralismo de 1857 o de limitarlo a ser la cámara revisora de 1836, pero sí para mantenerlo simplemente como colegislador. Sin embargo, esto requiere reformas de mayor envergadura. Serna opina que es más realista y conveniente avanzar hacia una descentralización gradual y selectiva, ${ }^{19}$ descentralización que repercuta también la actuación del Senado, reafirmando su papel histórico, en lugar de abandonarlo.

\section{El papel del Senado como órgano del Estado}

Las reformas de 1874 hicieron más que establecer un equilibrio al ejercicio del Poder Legislativo. El representar a las entidades federativas y servir de contrapeso en el proceso de formación de leyes como apunta Burgoa fue, quizás, lo que motivó el sistema bicameral de la Constitución de 1824 e, incluso, el del régimen centralista de la Constitución de 1836; pero el papel que el Constituyente de 1874 confirió al Senado, y

18 Serna de la Garza, op. cit., nota 16, p. 12.

19 Idem. 
que nuestra Constitución vigente recogió, va más lejos. El artículo 72 de la Constitución de 1857 incorporó, entre otras modificaciones, un apartado B que establece las facultades exclusivas del Senado:

Son facultades exclusivas del Senado:

I. Aprobar los tratados y convenciones diplomáticas que celebre el Ejecutivo con las potencias extranjeras.

II. Ratificar los nombramientos que el presidente de la República haga de ministros, agentes diplomáticos, cónsules generales, empleados superiores de Hacienda, coroneles y demás jefes superiores del ejército y armada nacional, en los términos que la ley disponga.

III. Autorizar al Ejecutivo para que pueda permitir la salida de tropas nacionales fuera de los límites de la República, el paso de tropas extranjeras por el territorio nacional y la estación de escuadras de otra potencia, por mas de un mes, en las aguas de la República.

IV. Dar su consentimiento para que el Ejecutivo pueda disponer de la guardia nacional fuera de sus respectivo Estados ó territorios, fijando la fuerza necesaria.

V. Declarar, cuando hayan desaparecido los poderes constitucionales Legislativo y Ejecutivo de un Estado, que es llegado al caso de nombrarle un gobernador provisional, quien convocará á elecciones conforme á las leyes constitucionales del mismo Estado. El nombramiento del gobernador se hará por el Ejecutivo federal con aprobación del Senado, y en sus recesos con la de la Comisión Permanente. Dicho funcionario no podrá ser electo gobernador constitucional en las elecciones que se verifique en virtud de la convocatoria que él expidiere.

VI. Resolver las cuestiones políticas que surjan entre los poderes de un Estado, cuando alguno de ellos ocurra en este fin al Senado, ó cuando con motivo de dichas cuestiones se haya interrumpido el orden constitucional, mediando un conflicto de armas. En este caso el Senado dictará su resolución, sujetándose á la Constitución general de la República y á la del Estado.

La ley reglamentará el ejercicio de esa facultad y el de la anterior.

VII. Erigirse en jurado de sentencia, conforme al artículo 105 de la Constitución. ${ }^{20}$

20 El Constituyente omitió adecuar el resto de la Constitución, de manera que subsistieron incongruencias internas en su texto durante todo el tiempo que estuvo en vigor. En particular, la facultad original del congreso de aprobar los tratados internacionales se mantuvo en la fracción XIII del artículo 72, al igual que se mantuvo la obligación del presidente de someter a la aprobación del congreso los tratados 
Esta reforma de 1874 debe entenderse en el contexto del artículo 39 de la Constitución de 1857, que corresponde al 40 de nuestra Constitución vigente: "Es voluntad del pueblo mexicano constituirse en una República representativa, democrática, federal, compuesta de Estados libres y soberanos en todo lo concerniente a su régimen interior; pero unidos en una Federación establecida según los principios de esta ley fundamental".

Distingue claramente el ámbito interno y este contraste evidencia el papel que la Federación —entendida como Estado, no como el gobierno federal- desempeña hacia el exterior; aunque no es explícita sobre el papel que juega el Estado al interior. Éste debe desentrañarse de otros artículos constitucionales, algunos de los cuales se apuntan aquí, pero es materia de un análisis diverso.

Los estados son libres y soberanos en todo lo que concierne a su régimen interno, pero cedieron su soberanía en lo que concierne al ámbito internacional. En efecto, el artículo 117 de la Constitución vigente prohíbe a los estados celebrar alianza, tratado o coalición con potencias extranjeras; e incluso contraer obligaciones o empréstitos con gobiernos de otras naciones y aun con sociedades o particulares extranjeros. Es más, la prohibición se extiende también a los nacionales cuando se trate de operaciones que deban pagarse en moneda extranjera o fuera del territorio nacional. Los estados también tienen prohibido llevar a cabo procesos de extradición, de acuerdo con el artículo 119. Éste mismo precepto confiere a los poderes de la unión la defensa de la nación ante invasión o violencia del exterior. Según dispone el artículo 118, salvo con autorización del congreso los estados en ningún tiempo pueden tener tropa permanente ni buques de guerra, y tampoco pueden hacer la guerra por sí a otras naciones (a menos que se trate de una invasión que implique un peligro inminente, aunque a este respecto se aprecia una distinción importante entre declarar la guerra, cosa que compete al presidente y el Congreso de la Unión, y hacer la guerra en caso de invasión).

internacionales, que estaba prevista en el texto original del artículo 85, fracción $\mathrm{X}$. Igualmente, permaneció inalterado el texto del artículo 126, que establecía que serían ley suprema de la unión los tratados internacionales suscritos por el presidente y aprobados por el congreso. Las reglas en materia de conflictos de leyes habrían resuelto la incongruencia interna entre disposiciones de la Constitución de 1857. Sin embargo, el error contenido en el artículo 126 pasó inadvertido a la Constitución de 1917 y no fue corregido sino hasta que fue reformado en 1934. 
Los estados carecen de personalidad jurídica internacional. Arteaga explica que la autonomía de la que gozan comprende exclusivamente problemas domésticos. ${ }^{21}$

En lo que concierne al régimen interior, la Constitución distingue el ámbito federal y el de las entidades federativas. Las materias se distribuyen entre uno y otro de acuerdo con el artículo 124. La Constitución crea los órganos del gobierno federal encargados de desempeñar las funciones legislativa, administrativa y judicial, y establece las bases que las Constituciones locales deberán observar al establecer los órganos de gobierno locales. Se trata, pues, de órganos del gobierno federal o de los gobiernos locales, según sea el caso.

Sin embargo, existe un tercer ámbito: el nacional o del Estado. Las relaciones internacionales caen en éste. El Estado es el encargado de conducir las relaciones internacionales. Actúa como un todo en el exterior. Raigosa precisa: "en el caso de las normas que componen el orden internacional... en ellas participa el Estado mexicano como una totalidad frente a otras totalidades análogas, otros estados o bien organismos internacionales". ${ }^{22}$ En el contexto de las relaciones internacionales, el Estado actúa como una totalidad también en el orden interno por virtud al sistema de recepción del derecho internacional por orden jurídico interno.

Varios autores se refieren a este tercer ámbito. Schmill lo llama orden constitucional ${ }^{23}$ al igual que Serna, que también lo llama orden constitucional del Estado federal total. ${ }^{24}$ Ortiz Ahlf, Vázquez Pando y Díaz hablan de la triplicidad de estratos del sistema jurídico mexicano e identifican el nacional, además del federal y local. ${ }^{25}$

21 Arteaga Nava, Elisur, Derecho..., cit., nota 2, p. 114.

22 Raigosa Sotelo, Luis, op. cit., nota 14, p. 194.

23 Schmill Ordóñez, Ulises, "Fundamentos teóricos del control de la constitucionalidad en México", en Vázquez, Rodolfo (comp.), Interpretación jurídica y decisión judicial, México, Fontamara, 2001, pp. 272 y ss.

24 Serna de la Garza, José María, "El poder de celebrar tratados internacionales y la división de competencias del sistema federal mexicano", en varios autores, Federalismo y regionalismo. Memoria del VII Congreso Iberoamericano de Derecho Constitucional, México, UNAM, Instituto de Investigaciones Jurídicas, 2002, pp. 525 y ss., formato PDF, disponible en http://www.bibliojuridica.org/libros/libro.htm?l=348.

25 Ortiz Ahlf, Loreta et al., Aspectos jurídicos del Tratado de Libre Comercio de América del Norte y sus acuerdos paralelos, 2a. ed., México, Themis, 1998, pp. 23 y ss. Véase también Vázquez Pando, Fernando, "Comentarios a la Convención sobre los 
Ortiz Ahlf y sus colaboradores comentan:

Aunque la doctrina suele diferenciar entre el estrato federal y el local, no suele en cambio referirse al primero de los estratos mencionados. Sin embargo, del análisis del sistema se desprende su existencia con claridad meridiana, ya que, desde luego, la Constitución misma no puede considerarse un ordenamiento federal ni local, pues ambas competencias son creadas por la Constitución, la cual les está supraordenada. ${ }^{26}$

Identifican la Constitución y el Constituyente como el acto y el órgano nacionales por excelencia, y añaden que no son los únicos. Se refieren también a la suspensión de garantías por el presidente, en tanto afecta la vigencia de disposiciones constitucionales. Mientras que los ámbitos federal y local están acotados por la distribución de competencias establecida en el artículo 124 constitucional, Schmill explica que existen funciones normativas que no pueden adscribirse ni al orden federal ni a los órdenes locales y da los mismos ejemplos que los autores ya citados, entre otros. ${ }^{27}$ Schmill precisa:

Cuando estos órganos llevan a cabo el procedimiento de reforma o adición a la Constitución, no están actuando en su calidad de órganos de la Federación o de los estados locales, pues no ejercitan competencia alguna de estos órdenes; por el contrario, ejercitan una competencia que sólo puede atribuirse al orden constitucional, puesto que con ella puede ser variada la decisión de competencias entre los órdenes federales o locales o ser modificadas disposiciones que sólo pueden ser adscritas al orden constitucional... Como no existen órganos especiales, aunque podrían existir, para llevar a cabo las funciones específicas que deben atribuirse al orden constitucional, las Constituciones de los Estados federales utilizan los órganos de los órdenes parciales subordinados para llevarlas a cabo, con lo cual el teórico del derecho, cuando expone el contenido de las normas constitucionales, debe tener mucho cuidado en distinguir cuales de las funciones son de los órdenes subordinados y cuales del orden constitucional. ${ }^{28}$

Contratos de Compraventa Internacional de Mercaderías a la luz del derecho mexicano", Anuario Jurídico, México, núm X, 1983, pp. 43 y 44.

26 Idem.

27 Schmill Ordóñez, Ulises, op. cit., nota 23, p. 275.

28 Ibidem, pp. 275 y 276. 


\section{Serna añade:}

[A]nte la inexistencia de órganos especiales, las funciones normativas del orden constitucional... son encargadas a órganos de la Federación, es decir, a órganos de uno de los órdenes jurídicos parciales. No obstante, en el ejercicio de esa función, dichos órganos no actúan en su calidad de órganos de la Federación, sino que ejercitan una facultad que en el esquema mexicano sólo puede atribuirse al orden constitucional..$^{29}$

La distinción que Schmill y Serna hacen entre órganos del Estado y funciones del Estado desempeñadas por órganos federales ante la inexistencia de órganos especiales parece menos relevante que el hecho de que la Constitución establece un ámbito diverso al federal y el local. En otras palabras, la cuestión central es que la Constitución crea un ámbito que envuelve al Estado como un todo, sin distingo de competencias federales y locales, ya sea que las funciones normativas que le están adscritas las desempeñe un órgano del Estado o un órgano federal ante la inexistencia de aquél.

Dicho esto, la interpretación más correcta es que la Constitución crea órganos que tienen un doble carácter: el de órganos federales y el de órganos del Estado, dependiendo de las funciones normativas que desempeñen. La doctrina y la jurisprudencia no han tenido ninguna dificultad para distinguir al Congreso Constituyente del Congreso General, aun cuando estén integrados por el mismo grupo de personas y desempeñen simultáneamente tanto la función legislativa federal como la de reformas o adiciones a la Constitución. Tampoco ha causado dificultad el doble carácter del presidente de la República como jefe de Estado y jefe de gobierno.

Tanto las funciones del Congreso General como las del Ejecutivo federal están limitadas por la distribución de competencias prevista en el artículo 124, y ni uno ni otro tiene facultades para injerir en los regímenes locales. ${ }^{30}$ Las facultades del Congreso General esencialmente están

29 Serna de la Garza, José María, "El poder de celebrar tratados...", cit., nota 24, p. 525.

30 Una excepción es la facultad del Ejecutivo de informar al Congreso de la Unión sobre el ejercicio del endeudamiento del gobierno del Distrito Federal. Éste, sin embargo, es un resabio de la época cuando el Ejecutivo federal era también el Ejecutivo del Distrito Federal. 
listadas de manera expresa en el artículo 73 de la Constitución. Sin embargo, es evidente que el Constituyente no enfrenta esas limitaciones.

Por lo que al presidente de la República se refiere, la Constitución le confiere facultades como Ejecutivo federal, es decir, como jefe del gobierno federal. Así, entre otras, tiene las de promulgar y ejecutar las leyes que expida el Congreso de la Unión, proveyendo en la esfera administrativa a su exacta observancia; de nombrar y remover libremente a los secretarios del despacho y a otros empleados de la unión; o convocar al congreso a sesiones extraordinarias, cuando lo acuerde la Comisión Permanente.

Empero, en su carácter de jefe de Estado, el presidente actúa en nombre de la Nación, y no está circunscrito al ámbito del gobierno federal. ${ }^{31}$ Como jefe de Estado tiene las facultades de dirigir la política exterior y celebrar tratados internacionales; nombrar a los ministros, agentes diplomáticos y cónsules generales, que son los representantes del Estado en el extranjero; disponer de la totalidad de la fuerza armada permanente o sea del ejército, de la armada y de la fuerza aérea para la seguridad interior y defensa exterior de la Federación, ya que la fuerzas armadas son instituciones de la nación; y declarar la guerra en nombre de los Estados Unidos Mexicanos previa ley del Congreso de la Unión.

El Congreso General, que es el Poder Legislativo federal, también actúa como órgano del Estado al declarar la guerra y admitir nuevos Estados a la unión federal.

El Senado también tiene esa doble naturaleza. Por un lado, es un órgano del Poder Legislativo federal y, como tal, representa a las entidades federativas en el proceso de formación de leyes federales. Sin embargo, el Senado también desempeña funciones como órgano del Estado Federado - más que como representante de las entidades federativas - al analizar la política exterior desarrollada por el Ejecutivo federal —en estricto sentido, por el presidente de la República-y aprobar los tratados internacionales y convenciones diplomáticas que éste celebre; al ratificar los nombramientos que haga el presidente de los ministros, agentes diplomáticos, cónsules generales; o al autorizarlo para que pueda permitir

31 Cfr. Ortiz Ahlf, Loreta et al., op. cit., nota 25, p. 27; Cossío Díaz, José Ramón y Rodríguez Huerta, Gabriela, El Senado de la República y las relaciones exteriores, México, Senado de la República-Instituto Tecnológico Autónomo de México-Miguel Ángel Porrúa, 2003, p. 59. 
la salida de tropas nacionales fuera de los límites del país o el paso de tropas extranjeras por el territorio nacional.

Compete al presidente de la República conducir las relaciones internacionales y celebrar tratados internacionales, es decir, negociarlos y suscribirlos. Sin embargo, para que los tratados puedan obligar al Estado mexicano se requiere de un acto complementario del Senado: la aprobación. Ésta, a su vez, cristaliza su incorporación al sistema jurídico interno como ley suprema de la unión, siempre que estén de acuerdo con la carta magna. Los tratados, además de constituir normas jurídicas válidas para el Estado en el plano internacional, se convierten también en normas jurídicas válidas, aplicables en el ámbito nacional, que engloba los ámbitos federal y local.

Los actos del Congreso General, como los del Ejecutivo federal, comprometen al gobierno federal, pero no al de las entidades federativas. Los actos del Congreso Constituyente, como ciertos actos del Congreso General, los del presidente de la República en su carácter de jefe de Estado y, en el caso de los tratados internacionales, los de éste y el Senado, comprometen o afectan al Estado en su conjunto.

La tesis de la Suprema Corte de Justicia de 1999 declara correctamente que el presidente suscribe los tratados internacionales como jefe de Estado. Sin embargo, en vista de los comentarios expuestos anteriormente, no se estima correcto que el Senado intervenga como representante de la voluntad de las entidades federativas y, por medio de su ratificación, oblige a sus autoridades. El Senado también interviene como representante de la voluntad de las entidades federativas en el proceso legislativo federal, pero no por ello obliga a sus autoridades.

Es el congreso, no el Senado, el que tiene la facultad de legislar en el ámbito federal. En el proceso de celebración y aprobación de tratados, el Senado interviene, al igual que el presidente, como representante del Estado. Los tratados internacionales obligan a las autoridades federales, estatales y municipales porque el presidente de la República y el Senado comprometen al Estado, que actúa unitariamente al exterior frente a la comunidad internacional.

\section{Los tratados internacionales y la distribución de competencias}

Algunos autores consideran que la "materia internacional" es de competencia federal, y pudiera considerarse que el Ejecutivo federal y el 
Senado no intervienen en el proceso sino como órganos del gobierno federal, en el desempeño de facultades específicas que la Constitución ha otorgado expresamente a la Federación. Hay quienes han llegado a considerar que la materia local se "federaliza" cuando es objeto de un tratado internacional. La postura es claramente equivocada. La distribución de competencias es una cuestión atinente a la organización del Estado y que, por lo mismo, compete exclusivamente al Estado. Sólo puede estar determinada por la Constitución, que es la norma fundamental que establece las bases de dicha organización. Es claro que la Constitución no confiere esas facultades al presidente y el Senado de la República, y ciertamente la comunidad internacional no puede, por la vía de los tratados internacionales, afectar la organización del Estado mexicano.

Es cierto que los tratados internacionales obligan a las entidades federativas, al igual que obligan al gobierno federal — es decir, obligan a la nación en su conjunto-, pero ello no dota de competencia en el ámbito local a las autoridades federales en aquellas materias que, siendo de competencia local, son objeto de un tratado internacional. Arteaga explica:

Los estados, por virtud de los tratados, no dejan de tener competencia en relación con las materias que aquéllos regulan, no así la Federación quien no adquiere para sí una competencia adicional. Es decir, no por el hecho de que una materia sea regulada en un tratado, es suficiente para considerar que es de la competencia de los poderes federales. La distribución competencial, como se ha afirmado, sólo la puede hacer la Constitución.

Lo único que logra el tratado es establecer bases generales obligatorias y comunes para los efectos de incitar y conducir la actuación de los poderes locales en materias que tienen que ver con las relaciones internacionales.

Un tratado celebrado en esas condiciones no es contrario a la Constitución ni altera la distribución de competencias que ella hace. ${ }^{32}$

Vázquez Pando comenta al respecto:

Queda pues claro que, al celebrarse un tratado sobre una materia local, ésta no deviene central, y el congreso carecerá de facultades para legislar

32 Arteaga Nava, Elisur, "Los tratados y las convenciones en el derecho constitucional", Revista de la Facultad de Derecho de México, México, UNAM, t. XXXIX, núms. 163-165, p. 135. 
en la materia al igual que carecía de ella con anterioridad a la celebración del tratado, salvo a través de las llamadas facultades implícitas, pero se da lugar a una ley que regula válidamente la materia y que tiene vigor en toda la República, es una ley general o nacional en la terminología que hemos adoptado. ${ }^{33}$

Otros autores sostienen que un tratado internacional que abarcara materias que son de la competencia de las entidades federativas sería inconstitucional. Opinan que la distribución de competencias entre Federación y estados afecta también la capacidad de celebrar tratados internacionales. Abarca, por ejemplo, señala: "Las materias civil y procesal civil, en cuanto que corresponden exclusivamente a los Estados, no pueden ser materia de tratado internacional". ${ }^{34}$

Trigueros adopta una postura un poco menos extrema. Reconoce la competencia del presidente y el Senado para celebrar y aprobar tratados internacionales, respectivamente, pero opina que las entidades federativas requieren incorporar las disposiciones de dichos instrumentos a través de sus órganos legislativos para que puedan tener eficacia en sus territorios:

Pretender que la convención o el tratado reformen directamente la legislación de los estados daría como resultado una invasión de competencias.

Si bien es cierto que el presidente de la república tiene facultad para celebrar tratados en virtud de lo dispuesto por la fracción X del artículo 89 constitucional, y de que por la fracción II del artículo 117 a los estados les está prohibida esta actividad, también lo es que el hecho de celebrar un tratado o convención no opera la federalización de la materia sobre la que éste versa. Interpretarlo de otra manera haría negatoria la distribución de competencias establecidas en el artículo 124 constitucional, y terminaría con el sistema federal. A través de la celebración de tratados y convenciones los poderes federales podrían acrecentar el número de facultades, en perjuicio de los estados y al margen de las disposiciones de la Constitución general. Este enfoque del problema sería, además violatorio de lo dispuesto por el artículo 15 de la Constitución que señala que no se pueden celebrar tratados o convenciones que alteren las garantías y los derechos

33 Vázquez Pando, op. cit., nota 25, p. 44.

34 Abarca L., Ricardo, "Facultades para celebrar tratados en materias reservadas a los Estados de la Federación", Revista de Investigaciones Jurídicas, México, Escuela Libre de Derecho, año 6, núm. 6, 1982, pp. 141-150. 
del hombre y del ciudadano otorgados por la Constitución. Dado que el sistema de distribución de competencias y el sistema federal mismo son una garantía del orden jurídico, establecidas para limitar y controlar el ejercicio del poder, la adjudicación de una facultad que no le corresponde, por el ejecutivo, violaría el precepto aludido.

Por estas razones, parece que la modificación directa no puede operar y que se requiere que las entidades incorporen las disposiciones de las convenciones en sus sistemas jurídicos propios, por medio de sus propios órganos legislativos. ${ }^{35}$

Ambas posturas son equivocadas. El análisis de los distintos artículos constitucionales que establecen facultades y prohibiciones en materia de política exterior y celebración de tratados lo corrobora. ${ }^{36}$

La posición de Abarca implicaría que el Estado mexicano ha limitado su propia capacidad jurídica ante la comunidad internacional, al estar imposibilitado para celebrar tratados en materias que son de la competencia de las entidades federativas por la interacción del artículo 124 constitucional con la prohibición contenida en el 117 del mismo ordenamiento. De ser correcta dicha postura, la prohibición evidentemente no se limitaría a la celebración de tratados, sino que alcanzaría a las relaciones internacionales en su conjunto, de modo que México no podría siquiera participar en foros internacionales en materia de adopción, protección de menores, etcétera, porque ningún funcionario mexicano, ni siquiera los embajadores que son los representantes del Estado en el exterior, tendría facultades para ello. El Estado sufriría de una autoimpuesta capitis diminutio internacional.

Los artículos 76, fracción I, y 89, fracción X, sin embargo, no precisan las materias específicas que pueden ser objeto de las relaciones internacionales del Estado mexicano, y ciertamente no limitan la conducción y revisión de la política exterior, y la celebración y aprobación de tratados a aquellas expresamente concedidas a funcionarios federales. Solís Hernández señala que la Constitución sólo enumera las materias de legislación federal, pero no las que pueden ser objeto de tratados internacio-

35 Trigueros, Laura, "Las convenciones internacionales y sus problemas de aplicación interna", Revista de la Facultad de Derecho de México, UNAM, t. XXXIX, núms. 163-165, p. 133.

36 Cfr. Serna de la Garza, José María, "El poder de celebrar tratados ...", cit., nota 24, pp. 521 y ss. 
nales. Añade que tal enumeración sería deficiente e incompatible con la suficiencia estatal de México en el exterior. ${ }^{37}$ Serna explica que el concepto de "política exterior" es de suyo impreciso y ambiguo, lo cual no quiere decir que no tenga contenido, sino que éste es determinable precisamente a través de decisiones de política que competen al presidente. ${ }^{38}$

En el análisis de la capacidad internacional del Estado mexicano debe considerarse también que la Constitución prohíbe a los estados de la República celebrar tratado, alianza o coalición, y contraer cualquier tipo de obligaciones con otras naciones. Según se señaló, los estados carecen de personalidad internacional y, por lo tanto, de capacidad para obligarse internacionalmente.

Las facultades del presidente y el Senado previstas en los artículos 76 y 89 en relación con el 133, aunado a la incapacidad internacional de las entidades federativas no significa que la Constitución haya restringido la suficiencia estatal de México en el exterior, para usar los términos de Solís Hernández o, dicho en una palabra, su soberanía. Ciertamente, el Estado puede autolimitarse; pero en nuestro caso tales limitaciones están expresas en la Constitución. Así, el artículo 15 prevé:

No se autoriza la celebración de tratados para la extradición de reos políticos, ni para la de aquellos delincuentes del orden común que hayan tenido en el país donde cometieron el delito, la condición de esclavos; ni de convenios o tratados en virtud de los que se alteren las garantías y derechos establecidos por esta Constitución para el hombre y el ciudadano.

El artículo 18, por su parte, dispone que, para la inclusión en un tratado internacional del traslado de reos extranjeros sentenciados por delitos del orden común, el Ejecutivo deberá contar con la solicitud previa de los gobernadores de los estados. La Constitución no establece otras limitaciones a la capacidad internacional del Estado.

La postura que Trigueros adopta salva la incapacidad jurídica, internacional del Estado que deriva de la que sostiene Abarca; pero implica limitaciones de orden práctico que igualmente se traducirían en una insuficiencia del Estado en el exterior, ya porque el Estado sería incapaz de obligarse internacionalmente si no cuenta con la anuencia del conjunto

37 Solís Hernández, Miguel, Los tratados y la Constitución; Ortiz Ahlf, Loreta et al., op. cit., nota 25, p. 19; y Arteaga Nava, Elisur, Derecho..., cit., nota 2, p. 121.

38 Cfr. Serna de la Garza, José María, "El poder de celebrar...", cit., nota 24, p. 524. 
de los gobiernos internos, porque el cumplimiento de México con sus obligaciones internacionales en materias del ámbito local estaría sujeto a la expresión de la voluntad de cada uno de ellos. La postura es claramente incongruente con el texto del artículo 133 constitucional porque implica que, en materias de la competencia de las entidades federativas, los tratados internacionales celebrados por el presidente y aprobados por el Senado no son ley suprema de la unión, a menos que cada una de las legislaturas estatales incorpore sus disposiciones en sus propios sistemas jurídicos. Trigueros, pues, priva de significado al término "unión" contenido en dicho artículo. Interpreta la expresión contenida en el precepto constitucional que se comenta simplemente como "ley federal suprema", que tiene un significado muy distinto. Desde el punto de vista semántico e histórico, la posición es insostenible.

La postura además presenta incongruencias internas insuperables. Haciendo una lectura laxa del artículo 124, admite que el presidente de la República tiene la facultad de celebrar tratados aun en materia local en virtud de lo dispuesto en el artículo 89, fracción X y la prohibición a las entidades federativas contenida en el artículo 117, fracción II; pero luego interpreta rígidamente el propio artículo 124 y opina que tales tratados carecen de efectos a menos que las legislaturas estatales incorporen sus preceptos a través de un acto legislativo. En otras palabras, como parte del supuesto de que el presidente y el Senado son órganos federales, admite la "federalización" de la materia local por lo que se refiere a la facultad del primero para celebrar tratados, pero la niega en lo que se refiere a su implementación en el orden jurídico interno. La postura que adopta Abarca, aunque incorrecta, por lo menos guarda congruencia interna al negar que el presidente tenga facultades para celebrar tratados en materia local.

Partiendo de la base de que los gobiernos estatales y el federal están en un plano de igualdad, pero se desenvuelven en ámbitos competenciales distintos, Trigueros no explica cómo es que los tratados internacionales requieren de un acto legislativo ulterior para tener eficacia en el ámbito local, pero no lo requieren en el ámbito federal. Niega que los tratados puedan ser autoaplicativos en el ámbito local, pero parece admitir que sí lo son en el federal. Trigueros distingue donde el Constituyente no lo hizo respecto del mismo texto constitucional y un acto - el tratadoformal y materialmente idéntico. Ciertamente el presidente y el Senado no son un órgano legislativo local, pero tampoco son el legislador fede- 
ral. Para ser congruente, tendría que concluirse que, en adición a la aprobación del Senado, también en el orden federal el Congreso General requiere incorporar las disposiciones de los tratados en el orden jurídico para que tuvieran eficacia. Ello, sin embargo, privaría de cualquier significado a la expresión "ley suprema de la unión" en su conjunto, porque en ausencia de treinta y dos actos legislativos individuales en el caso de las entidades federativas, y uno en el del gobierno federal, complementarios a la labor del presidente y el Senado, los tratados no serían ley, no serían supremos y no tendrían aplicación en la unión. La postura es claramente contraria al texto constitucional que sólo requiere la aprobación por el Senado de los tratados celebrados por el presidente.

Las consecuencias de orden práctico de dicha postura son que, o bien el Estado mexicano no podría asumir compromisos internacionales mientras no se legisle internamente para incorporar las disposiciones de los tratados con posterioridad a la adopción de éstos por el Senado, o bien el cumplimiento de los compromisos internacionales estaría sujeto a la voluntad individual de los poderes legislativos federal y estatales. Cualquiera que sea el caso, implica desconocer nuestro régimen federal.

No puede sostenerse que el Estado mexicano tenga una expresión hacia el exterior, que carezca de significado en el régimen interno. Es incorrecto que los tratados internacionales puedan comprender cualquier materia pues se terminaría con el sistema federal, según sugiere Trigueros. Por el contrario, las facultades conferidas al presidente y al Senado de la República como órganos del Estado, y el sistema de recepción del derecho internacional por el orden jurídico interno en el plano nacional, es decir, que el orden jurídico interno recoja la expresión del Estado hacia el exterior: son justamente una expresión del sistema federal mexicano.

\section{E. La jerarquía de los tratados en el orden normativo mexicano}

La Constitución coloca a los órganos del Estado en un plano superior a aquél en que se ubican los órganos federales y locales. Se aprecia con claridad en el caso del Constituyente, y no es distinto en los demás. Si el presidente de la República suspende garantías conforme al artículo 29 constitucional, las autoridades federales y locales no podrían dejar de observarla y un juez federal estaría impedido para conceder el amparo y protección de la justicia federal a las personas afectadas. Puede argumentarse que ello se debe a que, si se han suspendido garantías válidamente, éstas no pueden ser violadas; pero es claro que ese acto del presidente 
vincula a las autoridades federales y estatales. Desde luego, ni el Congreso de la Unión ni las legislaturas estatales podrían restablecerlas por ley y si lo intentaren, un juez federal estaría igualmente impedido para conceder el amparo a los particulares afectados. De forma similar, si el presidente y el Congreso General han declarado la guerra a otra nación, los gobernadores y legislaturas estatales no podrían decretar la exclusión de sus entidades respectivas de ese estado de guerra.

Serna, siguiendo la opinión de Schmill, explica que la función de crear normas internacionales a través de la celebración y aprobación de tratados es una función normativa del orden constitucional del Estado federal total. Añade que la Constitución encarga tales funciones a la Federación y precisa que "en el ejercicio de esa función, dichos órganos no actúan como órganos de la Federación, sino que ejercitan una facultad que en el esquema mexicano sólo puede atribuirse al orden constitucional". ${ }^{39}$ Más propiamente, crear normas internacionales es una función del orden nacional que la Constitución encarga a dos órganos del Estado: el presidente y el Senado de la República. Existen otras funciones del orden nacional - por ejemplo, la suspensión de garantías o la declaración de guerra- que la Constitución encarga a otros órganos.

El ámbito nacional está fuera de la competencia de los gobiernos federal y estatales, como el federal está fuera de la competencia de los gobiernos estatales y viceversa; pero en virtud de la distribución de competencias prevista en la Constitución - no exclusivamente en el artículo 124, según se explicó- los ámbitos de competencia federal y estatales no están fuera del alcance del ámbito nacional. Dicho en términos simples, los ámbitos federal y estatales están subordinados al nacional.

Hace falta una precisión adicional. Los tratados internacionales tienen una jerarquía superior al conjunto de las leyes del Congreso de la Unión. En la discusión sobre leyes constitucionales y leyes federales ordinarias derivada de la fórmula prevista en el artículo 133 de la Constitución no hay diferencia. Las leyes del Congreso de la Unión, ya sea que se distinga o no entre leyes constitucionales y leyes ordinarias - que no es objeto de este análisis - tienen una jerarquía inferior a los tratados internacionales, puesto que éstos son actos del Estado, mientras que aquellas son actos legislativos federales. Como tales, están sujetos a las limitaciones competenciales del artículo 124 y escapan del ámbito nacional. 


\section{CONCLUSIÓN}

En la jerarquía de leyes, pues, está la Constitución, los tratados en un segundo plano como actos del Estado, y las leyes federales y estatales en un tercer nivel, como leyes aplicables en sus ámbitos respectivos. Esta jerarquía normativa es consecuencia del sistema federal por el que México optó hace más de 130 años.

En la interpretación anterior de la corte, que fue abandonada al adoptar ésta el nuevo criterio en 1999, una ley del Congreso de la Unión podría haber colocado al Estado en una situación de ilicitud internacional. Conforme a dicha interpretación, una ley posterior del congreso podía haber derogado un tratado internacional o algunas de sus disposiciones, no obstante estar éste en pleno vigor en el plano internacional. Ello habría significado el incumplimiento por el Estado de sus compromisos internacionales, el cual, por supuesto, tiene consecuencias. Puede motivar represalias o actos de retorsión por parte de los demás Estados afectados, los cuales pueden consistir en la adopción de contramedidas, la obligación de pagar daños y perjuicios, la suspensión de concesiones u otras obligaciones contenidas en tratados, etcétera. Tales medidas - al igual que los tratados - afectan al Estado en su conjunto; no se limitarían al órgano gubernamental responsable de haber colocado al Estado en esa posición.

Nuestro sistema, sin embargo, guarda una congruencia interna y fortalece al Estado mexicano. El Estado, desde luego, es libre de celebrar y aprobar los tratados internacionales que le convengan, incorporándolos así al régimen jurídico nacional. Obviamente, ningún Estado puede desconocer o modificar sus obligaciones internacionales unilateralmente, aunque todo Estado es libre de denunciar tratados; pero en México ningún órgano de gobierno puede contravenir las políticas del Estado - fijadas por los órganos competentes del Estado - en el plano internacional. Por razón del sistema de incorporación de los tratados internacionales en el orden jurídico interno, las autoridades nacionales están obligadas a cumplirlos, observando la jerarquía superior de éstos sobre las leyes federales y locales en caso de conflicto.

El nuevo criterio de la corte refleja debidamente nuestro sistema federal y preserva la integridad de nuestro sistema jurídico en sus respectivos ámbitos. 


\section{CONCLUSIÓN}

En la jerarquía de leyes, pues, está la Constitución, los tratados en un segundo plano como actos del Estado, y las leyes federales y estatales en un tercer nivel, como leyes aplicables en sus ámbitos respectivos. Esta jerarquía normativa es consecuencia del sistema federal por el que México optó hace más de 130 años.

En la interpretación anterior de la corte, que fue abandonada al adoptar ésta el nuevo criterio en 1999, una ley del Congreso de la Unión podría haber colocado al Estado en una situación de ilicitud internacional. Conforme a dicha interpretación, una ley posterior del congreso podía haber derogado un tratado internacional o algunas de sus disposiciones, no obstante estar éste en pleno vigor en el plano internacional. Ello habría significado el incumplimiento por el Estado de sus compromisos internacionales, el cual, por supuesto, tiene consecuencias. Puede motivar represalias o actos de retorsión por parte de los demás Estados afectados, los cuales pueden consistir en la adopción de contramedidas, la obligación de pagar daños y perjuicios, la suspensión de concesiones u otras obligaciones contenidas en tratados, etcétera. Tales medidas - al igual que los tratados - afectan al Estado en su conjunto; no se limitarían al órgano gubernamental responsable de haber colocado al Estado en esa posición.

Nuestro sistema, sin embargo, guarda una congruencia interna y fortalece al Estado mexicano. El Estado, desde luego, es libre de celebrar y aprobar los tratados internacionales que le convengan, incorporándolos así al régimen jurídico nacional. Obviamente, ningún Estado puede desconocer o modificar sus obligaciones internacionales unilateralmente, aunque todo Estado es libre de denunciar tratados; pero en México ningún órgano de gobierno puede contravenir las políticas del Estado - fijadas por los órganos competentes del Estado - en el plano internacional. Por razón del sistema de incorporación de los tratados internacionales en el orden jurídico interno, las autoridades nacionales están obligadas a cumplirlos, observando la jerarquía superior de éstos sobre las leyes federales y locales en caso de conflicto.

El nuevo criterio de la corte refleja debidamente nuestro sistema federal y preserva la integridad de nuestro sistema jurídico en sus respectivos ámbitos. 